\title{
Safety of procedural sedation and analgesia in children less than 2 years of age in a pediatric emergency department
}

\author{
Shailendra Misra $\cdot$ Prashant V. Mahajan • \\ Xinguang Chen • Nirupama Kannikeswaran
}

Received: 13 June 2008 / Accepted: 18 July 2008 / Published online: 20 September 2008

(C) Springer-Verlag London Ltd 2008

\begin{abstract}
Background Although young age is considered a risk factor for adverse events related to procedural sedation and analgesia (PSA), data in very young children $(<2$ years of age) are lacking.

Aims The main objective of our study is to describe PSA in children $<2$ years of age in an inner city tertiary care pediatric emergency department (PED).

Methods We conducted a retrospective chart review from January 2005 to June 2007 of children $<2$ years of age who received PSA in our PED. We collected demographic variables, indication for and medications used for PSA, adverse
\end{abstract}

The views expressed in this paper are those of the author(s) and not those of the editors, editorial board or publisher.

\section{S. Misra}

Carman and Ann Adams Department of Pediatrics,

Division of Emergency Medicine,

Children's Hospital of Michigan,

3901 Beaubien Blvd.,

Detroit, MI 48201, USA

\section{P. V. Mahajan}

Carman and Ann Adams Department of Pediatrics,

Children's Hospital of Michigan, Wayne State University,

3901 Beaubien Blvd.,

Detroit, MI 48201, USA

\section{Chen}

Wayne State University,

Detroit, MI 48202, USA

N. Kannikeswaran $(\bowtie)$

Carman and Ann Adams Department of Pediatrics,

Division of Emergency Medicine,

Children's Hospital of Michigan, Wayne State University,

3901 Beaubien Blvd.,

Detroit, MI 48201, USA

e-mail: nkannike@dmc.org events (AE) related to PSA, and interventions performed to treat them.

Results Of the children who received PSA, 14.5\% (180/ 1,235 ) were $<2$ years of age of whom 173 were included for the analysis; 73\% (126/173) of the study subjects were between 1 and 2 years of age, 54.3\% (94/173) were male, and 96.5\% (167/173) belonged to American Society of Anesthesiologists class 1 . Incision and drainage $(45.0 \%, 78 / 173)$ and laceration repair $(32.4 \%, 56 / 173)$ were the two most common indications for PSA. Ketamine and midazolam was the most common combination medication used for PSA $(62.4 \%, 108 / 173)$. Sedation was deemed ineffective in 5.8\% $(10 / 173)$ of the children. There were only two failed sedations; $5.8 \%(10 / 173)$ of the children experienced AE with most being minor [oxygen desaturations $1.7 \%$ (3/173), emesis $2.3 \%(4 / 173)$, and others $1.2 \%(2 / 173)]$. One child experienced serious $\mathrm{AE}$ in the form of apnea and bradycardia requiring intubation.

Conclusions Our data suggest that children under 2 years of age can be sedated effectively without increased risk of $\mathrm{AE}$ in a PED.

Keywords Pediatric · Procedural sedation .

Conscious sedation $\cdot$ Analgesia $\cdot$ Adverse events

\section{Introduction}

Providing relief from pain and anxiety associated with diagnostic and therapeutic procedures has become an ethical imperative in children as well as a measured quality indicator from the family's perspective. This, along with a tremendous increase in the number of procedures performed on children outside the operating room, has led to non-anesthesiologists, particularly emergency physicians, taking a key role in the 
administration of procedural sedation and analgesia (PSA) to children. It has been estimated that roughly a quarter million children will receive PSA in the emergency departments (EDs) annually and that children under 2 years of age constitute roughly $20-30 \%$ of those $[1,2]$. It has been shown that pain in infants and toddlers is poorly recognized and documented [3, 4], predisposing them to receive less analgesia when compared with older children [5]. Commonly used medications for PSA such as ketamine are relatively contraindicated in very young children $(<6$ months of age) because of an association with increased risk of airway complications [6]. Inadequate sedation and analgesia predisposes to procedural failure, parental anxiety and dissatisfaction, and poor quality of care. The anatomic differences in the airway like smaller airway diameter, longer and floppy epiglottis, and the physiologic differences in drug metabolism between younger and older children could predispose younger children to a higher risk for adverse events related to sedation. Studies have shown contrasting results regarding association of age and adverse events related to PSA. While some studies have found children less than 2 years of age to be at an increased risk for adverse events related to PSA [7, 8], other studies have found no association between age and adverse events related to PSA [9, 10]. To our knowledge, there have been no studies that have focused exclusively on PSA in children less than 2 years of age. The main objective of our study is to describe PSA in children less than 2 years of age in the ED of a tertiary care children's hospital. Additionally, we will describe the indications for PSA, medications used, efficacy of sedation, and adverse events related to sedation in this group of children.

\section{Methods}

We conducted a retrospective chart review of medical records, including sedation records of all children less than 2 years of age who underwent PSA in our ED over a period of 2.5 years from January 2005 to June 2007. Our ED is a level 1 trauma center of a tertiary care, freestanding children's hospital with greater than 90,000 visits a year. Study subjects were identified using their date of birth and the Current Procedural Terminology (CPT) code used for procedural sedation in the ED (99141). All patients who undergo PSA in the ED have a standardized nursing sheet that records all events during the PSA procedure till discharge from the ED. Children who received only pain medication, or analgesia, and those who underwent sedation in the imaging department by the sedation team were excluded from the study.

We used a standardized data abstraction sheet to collect patient demographic variables, past medical history including American Society of Anesthesiologists (ASA) class, indications and medications used for PSA, and service of the phy- sician (for example ED attending or consultant services like pediatric surgery, hand surgery, etc.) performing the procedure. We collected data on effectiveness of sedation, adverse events related to sedation, the interventions performed to overcome the adverse events, and ED disposition. For the purposes of the study, the following were considered as adverse events: oxygen desaturations less than $93 \%$ for greater than $15 \mathrm{~s}$, apnea, aspiration, laryngospasm, bradycardia, hypotension, paradoxical reaction, emesis, and any other that were reported by the sedating physician as an adverse event. Sedation was deemed as inadequate if the procedure was completed but with significant patient distress as documented in the nursing notes or movement during the procedure. Failed sedation was defined as the inability to complete the procedure in the ED. All data were abstracted and entered by the principal investigator to maintain consistency. All data were double entered for accuracy. This study was approved by the Institutional Review Board.

Statistical analysis was conducted using the commercial software SAS v. 9.1 (SAS Institute Inc., Cary, NC, USA). Descriptive statistics (frequency, mean, standard deviation, and $95 \%$ confidence interval) was used to summarize the characteristics of the study sample. The chi-square test and Student's $t$-test were used to compare the differences in the number of medications used and medication dosages between patients with adequate sedation versus those with inadequate sedation.

\section{Results}

Over the study period of 2.5 years, there were a total of 225,750 patient visits to the ED. A total of 1,235 PSAs were performed, of which $14.6 \%(180 / 1235)$ were performed in children under the age of 2 years. Of these, seven children were excluded from review and analysis. We were unable to obtain medical records for 5 children, 1 child received only analgesia, and 1 child was sedated by the sedation service for diagnostic imaging, leaving 173 patients eligible for analysis. The majority of patients $(73 \%, 126 / 173)$ receiving PSA were between 1 and 2 years of age (Fig. 1), 54.3\% (94/173) were male, and $96.5 \%(167 / 173)$ belonged to ASA class 1 . Incision and drainage $(45.0 \%, 78 / 173)$ and laceration repair $(32.4 \%$, $56 / 173$ ) were the two most common indications for PSA in this age group (Fig. 2). The procedure was performed by the consultant services (non-ED attending) in 77\% (133/173) of the patients. The average duration of the procedure requiring PSA was $17.3 \pm 13.9$ minu The majority of the children received a combination of two medications for PSA $(80.4 \%$, $139 / 173)$. Ketamine/midazolam $(62.4 \%, 108 / 173)$ was the most common combination medication used for PSA followed by morphine/midazolam $(16.1 \%, 28 / 173)$ reflective of institutional practice. 


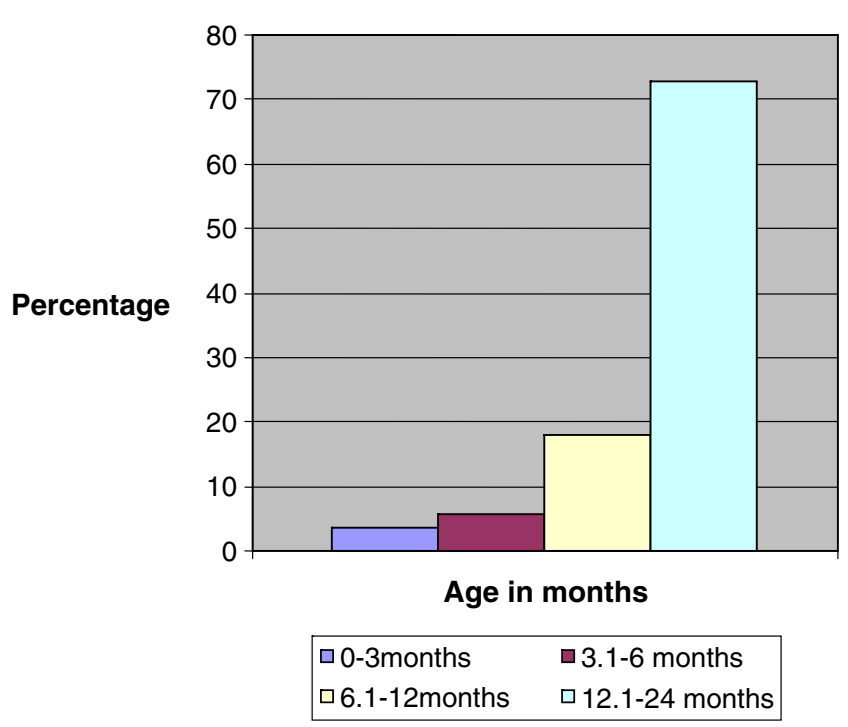

Fig. 1 Age distribution of study population

Sedation was "inadequate" in $5.8 \%(10 / 173)$ of the patients. There was no difference in patient age, number of medications used, and mean weight-based dosage of ketamine and morphine used between those with adequate versus inadequate sedation. The mean dosage of midazolam used was slightly higher in those children with inadequate sedation (Table 1). The planned procedure could not be completed successfully in only two children. Both of these were procedure failures and not sedation failures. The first case was a 2-month-old male child who was adequately sedated with ketamine and midazolam but failed reduction of an incarcerated inguinal hernia. This child also subsequently developed apnea related to PSA. The second patient was a 6-month-old female child who had to be taken to the operating room after failure of reduction of hernia under sedation with morphine $(0.2 \mathrm{mg} / \mathrm{kg})$ and midazolam $(0.1 \mathrm{mg} / \mathrm{kg})$.

Of the patients, $5.8 \%$ (10/173) experienced adverse events related to PSA (Table 2). Most (9/10) of these adverse events were minor in nature and included transient oxygen desaturations $(1.7 \%, 3 / 174)$, emesis $(2.3 \%, 4 / 173)$, and others $(1.2 \%$, 2/173), which included snoring and development of transient stridor. All these adverse events resolved with minimal interventions including repositioning the airway, oral suctioning, and oxygen supplementation.

One study subject experienced a serious adverse event, in the form of apnea and bradycardia, which required intubation. This was a 2-month-old male child with a history of recent upper respiratory tract infection and an overnight admission for bronchiolitis 1 week prior to the visit that required PSA. $\mathrm{He}$ required PSA for an incarcerated right-sided inguinal hernia. He received two doses of ketamine (total of $2 \mathrm{mg} / \mathrm{kg}$ ) and two doses of midazolam (total of $0.2 \mathrm{mg} / \mathrm{kg}$ ). Approximately $30 \mathrm{~min}$ after the failed reduction he developed persistent hypoxia and bradycardia which did not respond to supplemental oxygen or airway maneuvers and subsequently became apneic requiring endotracheal intubation. He was extubated 2 days later and had an uncomplicated recovery.

\section{Discussion}

Our study results suggest that PSA is safe and can be performed successfully in children less than 2 years of age. These results are consistent with previous studies which have demonstrated the proficiency of emergency medicine physicians to deliver PSA effectively in children of all age groups $[9,11$, 12]. There were only two failed sedations in our study. Both our "failed sedations" occurred in the youngest age group

Fig. 2 Indications for PSA

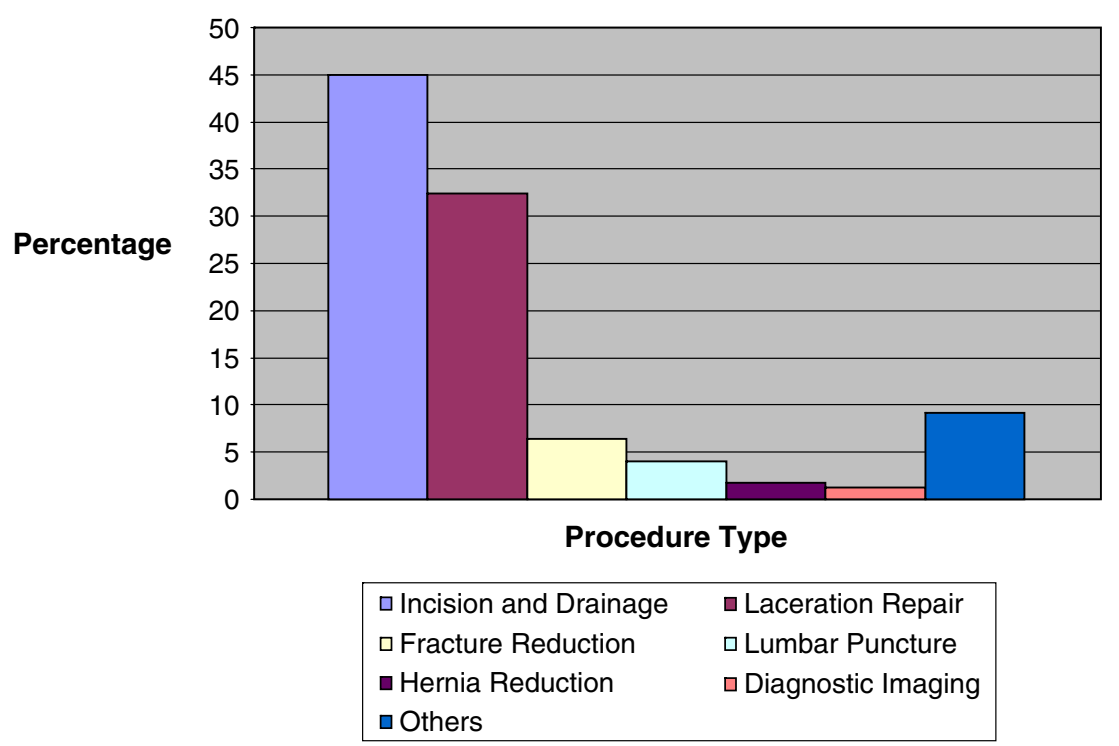


Table 1 Comparison of children with adequate versus inadequate sedation

\begin{tabular}{|c|c|c|c|c|c|}
\hline \multirow[t]{2}{*}{ Variable } & \multicolumn{2}{|c|}{ Adequate sedation } & \multicolumn{2}{|c|}{$\begin{array}{l}\text { Inadequate } \\
\text { sedation }\end{array}$} & \multirow[t]{2}{*}{$p$ value } \\
\hline & $n$ & Percentage & $n$ & Percentage & \\
\hline \multicolumn{6}{|l|}{ Age } \\
\hline $0-1$ years & 43 & 93.5 & 3 & 6.5 & 0.820 \\
\hline $1-2$ years & 118 & 94.4 & 7 & 5.6 & \\
\hline \multicolumn{6}{|c|}{ No. of medication(s) received } \\
\hline One & 22 & 13.8 & 2 & 20.0 & 0.582 \\
\hline Two or more & 138 & 86.2 & 8 & 80.0 & \\
\hline Medication dosage & $n$ & $\mathrm{mg} / \mathrm{kg}(\mathrm{SD})$ & $n$ & $\mathrm{mg} / \mathrm{kg}(\mathrm{SD})$ & \\
\hline Morphine & 29 & $0.140(0.078)$ & 2 & $0.120(0.071)$ & 0.731 \\
\hline Versed & 133 & $0.099(0.057)$ & 8 & $0.144(0.045)$ & 0.032 \\
\hline Ketamine & 128 & $1.211(0.568)$ & 8 & $1.326(0.348)$ & 0.571 \\
\hline
\end{tabular}

( $<6$ months of age), were procedure failures, and occurred during hernia reduction. This may underscore the need for reduction in the operating room rather than in the emergency department for the youngest children.

Interestingly, abscess incision and drainage was the most common indication for PSA in our study population. Other studies have reported that fracture reduction and laceration repair are more common indications $[9,12]$, and the difference in indications could be reflective of our study population or could reflect the reported increase in the ED visits for skin and soft tissue infections secondary to the emergence of community-acquired methicillin-resistant Staphylococcus aureus [13].

Our study demonstrates a low adverse event rate related to PSA in children less than 2 years of age. More importantly, most of the observed adverse events were minor and transient requiring only minimal intervention. Malviya et al. [8] in their study of adverse events related to sedation of children by non-anesthesiologists concluded that young age (less than 1 year of age) was a predictor of adverse events. However, the majority of patients in their study underwent sedation for diagnostic imaging and three fourths of the children were sedated with chloral hydrate, a drug that is not commonly used for PSA in the emergency department. Although Peña et al. [9] in their prospective study of adverse events related to PSA in a pediatric emergency department reported that one third of the observed total adverse events occurred in children up to 2 years of age, in their final analysis they were unable to find a difference between those who experienced adverse events and those who did not, with respect to age.

We did have one serious adverse event related to PSA in our study. This patient serves to highlight that safety of PSA is dependent on patient characteristics and that adequate monitoring is essential during and after the procedure until the patient is ready for discharge. It also emphasizes the need for physicians providing PSA to have necessary skills to rescue the patient from a deeper level of sedation than that intended for the procedure and provide appropriate cardiopulmonary support if needed [14].

\section{Limitations}

The biggest limitation to our study was its retrospective nature, which could have limited the amount of information

Table 2 Adverse events related to procedural sedation and analgesia

\begin{tabular}{|c|c|c|c|c|c|}
\hline Age (months) & Sex & Procedure & Medication dose (mg/kg) & Adverse event & Treatment \\
\hline 2 & M & Hernia reduction & $\begin{array}{l}\text { Midazolam (2) } \\
\text { Ketamine }(0.2)\end{array}$ & Apnea, bradycardia & Intubation \\
\hline 15 & M & Laceration repair & $\begin{array}{l}\text { Midazolam }(0.17) \\
\text { Ketamine }(1.29)\end{array}$ & Oxygen desaturation & Oxygen supplementation \\
\hline 10 & M & Incision \& drainage & $\begin{array}{l}\text { Midazolam }(0.09) \\
\text { Ketamine }(0.95)\end{array}$ & Oxygen desaturation & Oxygen supplementation \\
\hline 22 & M & Laceration repair & $\begin{array}{l}\text { Midazolam }(0.13) \\
\text { Ketamine }(1.52)\end{array}$ & Oxygen desaturation & Oxygen supplementation \\
\hline 15 & $\mathrm{~F}$ & Laceration repair & $\begin{array}{l}\text { Midazolam (0.13) } \\
\text { Ketamine (1.02) }\end{array}$ & Stridor & $\begin{array}{l}\text { Airway repositioning, } \\
\text { racemic epinephrine }\end{array}$ \\
\hline 9 & M & Incision \& drainage & Ketamine $(0.98)$ & Snoring & Airway repositioning \\
\hline 22 & M & Laceration repair & $\begin{array}{l}\text { Midazolam (0.13) } \\
\text { Ketamine (1.52) }\end{array}$ & Vomiting & Suction \\
\hline 4 & M & Incision \& drainage & $\begin{array}{l}\text { Midazolam }(0.14) \\
\text { Morphine }(0.21)\end{array}$ & Vomiting & Suction \\
\hline 23 & M & Laceration repair & $\begin{array}{l}\text { Midazolam }(0.09) \\
\text { Ketamine }(0.89)\end{array}$ & Vomiting & Suction \\
\hline 23 & $\mathrm{~F}$ & Laceration repair & $\begin{array}{l}\text { Midazolam (0.09) } \\
\text { Ketamine }(0.94)\end{array}$ & Vomiting & Suction \\
\hline
\end{tabular}


that was available. We reviewed not only the medical records of the study children but also the sedation records. The sedation records were audited every 3 months during the study period to ensure completeness of data recorded in these records. There could have also been variation amongst physicians and nurses as to what constitutes an adverse event related to PSA leading to overreporting or underreporting of the adverse event rate. But this under/overreporting is less likely because of a standardized monitoring plan for all patients undergoing PSA in the ED. We also did not study the adverse events after discharge from the emergency department. This study was undertaken at a tertiary care pediatric emergency department and the findings may not be applicable to other settings with different levels of training of the sedation providers and different monitoring practices. Our center also uses ketamine predominantly for PSA. The adverse event rate and profile may be different in other centers which use other medications for PSA.

\section{Conclusion}

Our study shows that PSA can be administered effectively and safely with few adverse events to children less than 2 years of age in a pediatric emergency department.

Conflicts of interest None.

\section{References}

1. Sacchetti A, Stander E, Ferguson N, Maniar G, Valko P (2007) Pediatric procedural sedation in the community emergency department: results from the ProSCED registry. Pediatr Emerg Care 23 (4):218-222

2. Cravero JP, Blike GT, Beach M, Gallagher SM, Hertzog JH, Havidich JE, Gelman B, Pediatric Sedation Research Consortium (2006) Incidence and nature of adverse events during pediatric sedation/anesthesia for procedures outside the operating room: report from the Pediatric Sedation Research Consortium. Pediatrics 118:1087-1096
3. Drendel AL, Brousseau DC, Gorelick MH (2006) Pain assessment for pediatric patients in the emergency department. Pediatrics 117:1511-1518

4. Singer AJ, Gulla J, Thode HC Jr (2002) Parents and practitioners are poor judges of young children's pain severity. Acad Emerg Med 9:609-612

5. Alexander J, Manno M (2003) Underuse of analgesia in very young pediatric patients with isolated painful injuries. Ann Emerg Med 41:617-622

6. Green SM, Krauss B (2004) Clinical practice guideline for emergency department ketamine dissociative sedation in children. Ann Emerg Med 44(5):460-471

7. Malviya S, Voepel-Lewis T, Prochaska G, Tait AR (2000) Prolonged recovery and delayed side effects of sedation for diagnostic imaging studies in children. Pediatrics 105:e42

8. Malviya S, Voepel-Lewis T, Tait AR (1997) Adverse events and risk factors associated with the sedation of children by nonanesthesiologists. Anesth Analg 85:1207-1213

9. Peña BM, Krauss B (1999) Adverse events of procedural sedation and analgesia in a pediatric emergency department. Ann Emerg Med 34:483-491

10. Hoffman GM, Nowakowski R, Troshynski TJ et al (2002) Risk reduction in pediatric procedural sedation by application of an American Academy of Pediatrics/American Society of Anesthesiologists process model. Pediatrics 109:236-243

11. Pershad J, Godambe SA (2004) Propofol for procedural sedation in the pediatric emergency department. J Emerg Med 27:11-14

12. Pitetti RD, Singh S, Pierce MC (2003) Safe and efficacious use of procedural sedation and analgesia by nonanesthesiologists in a pediatric emergency department. Arch Pediatr Adolesc Med 157:1090-1096

13. Pallin DJ, Egan DJ, Pelletier AJ, Espinola JA, Hooper DC, Camargo CA (2008) Increased US emergency department visits for skin and soft tissue infections, and changes in antibiotic choices, during the emergence of community-associated methicillin-resistant Staphylococcus aureus. Ann Emerg Med 51:291-298

14. American Academy of Pediatrics, American Academy of Pediatric Dentistry, Coté CJ, Wilson S, Work Group on Sedation (2006) Guidelines for monitoring and management of pediatric patients during and after sedation for diagnostic and therapeutic procedures: an update. Pediatrics 118:2587-2602

Shailendra Misra The principal investigator, Dr. Misra, is a third year graduating fellow in Pediatric Emergency Medicine at the Children's Hospital of Michigan. He completed his pediatric residency training at the Medical College of Ohio at Toledo and plans to work in Toledo upon graduation. His areas of interest are procedural sedation for children in the emergency department. 